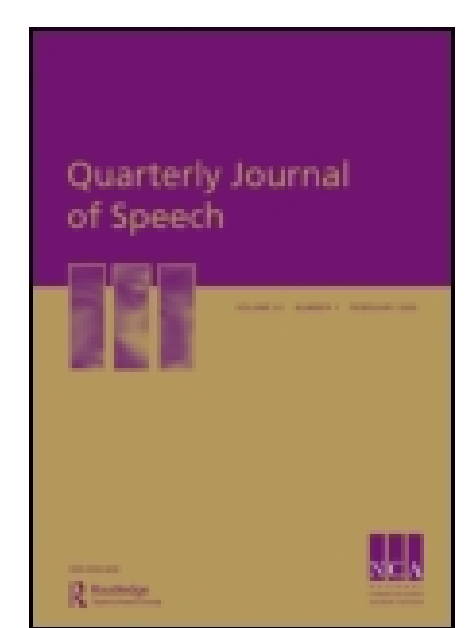

Quarterly J ournal of Speech

Publication details, including instructions for authors and subscription information:

http:// www.tandfonline.com/loi/ rajs20

\title{
Correction of speech defects in a public school system
}

Pauline B. Camp

${ }^{a}$ Supervisor of Oral School for the Deaf, and of the Corrective Speech Work, Grand Rapids, Michigan

Published online: 05 J un 2009.

To cite this article: Pauline B. Camp (1917) Correction of speech defects in a public school system, Quarterly J ournal of Speech, 3:4, 304-309, DOI: 10.1080/00335631709360625

To link to this article: http:// dx. doi. org/ 10.1080/0033563170936062

\section{PLEASE SCROLL DOWN FOR ARTICLE}

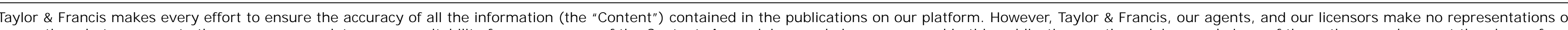

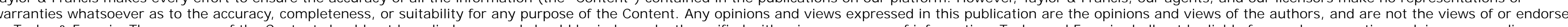

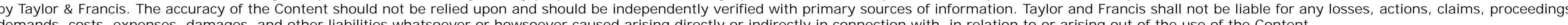
demands, costs, expenses, damages, and other liabilities whatsoever or howsoever caused arising directly or indirectly in connection with, in relation to or arising out of the use of the Content.

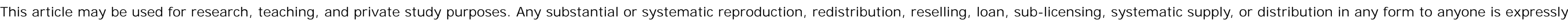
forbidden. Terms \& Conditions of access and use can be found at http://www.tandfonline.com/page/terms-and-conditions 


\section{CORRECTION OF SPEECH DEFECTS IN A PUBLIC SCHOOL SYSTEM}

PAULINE B. CAMP

Supervisor of Oral School for the Deaf, and of the Corrective Speech Work Grand Rapids, Michigan

T XPERIMENTAL studies within the past five years have 1) established as a fact the theory that the majority of individuals have balanced mental abilities for all school subjects; and this fact is the basis for the formation of curriculums in public school systems. Because they possess this inherent correlation of mental capacities, the greater number of children can easily adjust themselves not only to the school curriculum, but also to the ordinary affairs of life; and for both social and economical reasons these are the children who have received first consideration from educational systems. Except where the variation from type has been great as in the case of the deaf, blind, feeble-minded, epileptic, etc., but little, if any, attention has been given to those individuals who are illy adjusted to the program of school, and of life.

But the problem of individual adjustment is now beginning: to make its claim. Its greatest demand for recognition is probably coming not from within the school system, but from without. It is a social, psychological, and medical problem and is beginning to be discussed from these three viewpoints.

Doctor Bronner, in her book, "Psychological Abilities and Disabilities," speaking of the failure of school systems to meet the needs of the children who deviate from the average, says, ${ }^{66}$ Educational dissatisfaction is a very frequent beginning of what may develop into a long career of misdeeds. From our studies. of delinquents, we believe that misunderstanding and neglect. of children with particular abilities and disabilities leads to truancy and thence to consequences the seriousness of which is too little appreciated."

It is good for our school systems to be thus criticised by 2 trained psychologist and social worker of Dr. Bronner's experience. 
There are criticisms and reforms coming from within educational circles, too. Many of our best educators now have for their ideal a school system so elastic as to meet the needs of all the children, not just the majority. I am very glad to be working with a Board of Education who possess this ideal. Grand Rapids is making an effort to understand and correct the special disabilities of all children in her schools.

It is true, as Dr. Bronner reminds us, that many questions of particular abilities and disabilities cannot yet be solved, but psychologists, physicians, college professors and teachers trained for special work are all devoting time and study to the various phases of the problem; and we have the right to feel hopeful that these children who are "normal except for special defects," or, "subnormal in all but a special ability" will soon receive careful scientific diagnosis and training.

The disability in particular which possibly interferes with individual adjustment more than any other except the very marked defects referred to above is that of a speech defect. A child with a speech defect is not only held back in school because of his inability to express himself, but is also poorly adjusted to social and economic conditions when he is through with school.

Dr. Wile, of the New York City Board of Education, in his article, "The Economic Value of Speech Correction," says, "The economic cost of speech defect is registered in the limitation of the occupations that are available for individuals who have speech delinquencies. The more pronounced the defect, the more limited the field of activity. Another economic gain to be secured through speech correction is the prevention of industrial accidents."

In discussing the subject further from the moral and also economical aspect, Dr. Wile says, "The importance of discouragement, anxiety, family distress, embarrassment, diffidence, and shyness upon the development of high moral character cannot be estimated. Wherefore among delinquents, speech defects are noted with greater frequency than a normal population. If speech correction can prevent children from moral degeneration, its economic usefulness is enhanced."

A few of the medical profession, too, are beginning to give serious consideration to the subject of speech defects. Dr. Hud- 
son Makuen of Philadelphia has worked on this problem for several years; and the most valuable contribution we have, at least the most noteworthy one written by an American, is the book, "Stuttering and Lisping," by Dr. Scripture, formerly of Columbia University. Dr. Blanton of the University of Wisconsin is also doing a very valuable work along this line.

Dr. James Sonnett Green realizes the importance of speech correction and treats it in an article which he read before the New York meeting of the National Teachers' Association, 1917. He gives the literary history of speech defects and discusses the pathological condition which accompanies this disability. $\mathrm{He}$ says, "Efficiency and ease seem to go together as characteristic of mental strength and economy. 'Living at the tips of one's nerves' through an impediment of speech tends to develop vicious circles of nervous instability, resulting in an increase of criminals, prostitutes, and general failures." He concludes with the question:

"May we not hope that through the coopperation of education and medicine in the task of curing disorders of speech the new generation will go forth better equipped for the battle of life?"

The prevalence of speech defects is not generally realized. Conradi gathered statistics in a number of cities, surveying in all about 87,400 children. ${ }^{~ " O f ~ t h e s e, ~ t w o ~ a n d ~ f o r t y-s i x ~ h u n d r e d t h s ~}$ had speech defects, and eighty-seven hundredths of one per cent stuttered, and one and fifty-nine hundredths of one per cent had other speech defects." Dr. Wallin of St. Louis examined 89,077 children and found that $2.7 \%$ had well-marked speech defects. His statistics show $1.6 \%$ of lispers, $7 \%$ of stutterers, .4 of one per cent with some other form of speech defect.

Dr. Blanton, of the University of Wisconsin, visited seventeen of the Madison schools and surveyed 4,862 children. The following percentages were found:

Total number of speech defects ......... 5.69\%

Stutterers ........................ . $2 \%$

Lispers ....................... $3.27 \%$

Miscellaneous ..................... I.7I\%

Dr. Blanton makes this explanation: "The percentage of stutterers, .72, is practically the same as that found by Wallin, 
.7, but the percentage of lispers and miscellaneous defects is about three times as large. . . . This is due, I think, to the fact that the figures were gathered in the St. Louis survey by a questionnaire, and many of the cases of thick and indistinct speech and cases of lisping were not reported by the class teacher, not accustomed to reporting speech defects."

If we are going to handle this problem, it is of vital importance that we organize school instruction in the elementary grades for speech correction; for speech becomes habituated by the age of pubescence. After that age it is a difficult matter to correct a disability of speech.

There are now two methods in practice for the formation of speech classes in the public schools in this country. One segregates the children with speech defects for all their school instruction; the other segregates them for their lesson in speech only and they then return to their regular classes for instruction in other subjects. The latter, I think, is the better plan. It seems to me unwise to segregate children whose faculties are normal, or almost so, but who are suffering from any particular defect which makes them unusual. I feel that it is better to help them re-adjust themselves in a normal environment. Of course, where the defect is extreme it is sometimes necessary to segregate for at least a time, but this should be the exception, not the rule. We have found only one case of speech defect in Grand Rapids that we thought so extreme as to need the attention of a special teacher of speech for all of his instruction.

Classes for the correction of speech defects were organized in the Grand Rapids schools last year. The mechanical arrangement was as follows: twelve classes were arranged for in five different schools with a half hour a day for each class. The children were grouped according to age, kind of defect, etc., and a teacher with special training for the correction of speech was sent from school to school to give the instruction.

Our plans for this year are practically the same as for last excepting that we have two more special teachers and will be able to reach a greater number of schools and give more time to individual cases.

There are two different classes of speech defects. First, those due to organic causes; second, those which have a mental cause and which we call functional defects. 
The chief organic defect is lisping. This is often caused by a mal-occlusion of the teeth. If there is a decided protrusion of the lower jaw, the lower teeth will come in front of the upper when the teeth are closed. With this condition of teeth we almost always have lisping or imperfect speech. The same is also true if the upper teeth protrude too far in front of the lower. The service of an orthodontist is needed to correct this condition of the teeth, but the speech can be much improved without orthodontia.

As a result of adenoids, many children have a high palatal arch which also causes lisping and imperfect speech.

Cleft palate, thick and imperfectly developed tongue, diphtheritic paralysis of the soft palate are all organic causes of indistinct and nasal speech which can be greatly benefited by a skilled speech teacher. Of course a cleft palate must be operated on before speech instruction can be of help.

Under the head of functional speech disorders we have stuttering, neurotic lisping, and hysterical aphasia. The most important of these is stuttering. There have been many interesting and unique theories advanced as to the cause of stuttering, and many fake schools established for its cure. Appelt, in regard to therapeutics, claims that the occasional success of all these different schools is due to the part that auto-suggestion plays, and that the cure can only be temporary.

Appelt's own "cure" is due partly to auto-suggestion, but more directly to psycho-analysis and re-adjustment. He believes the cause to be a mental conflict and claims that by uncovering the complex, the speech impediment will disappear.

This, too, is Scripture's theory as to cause, and almost all of the speech specialists in this country follow him. But Gutzman and a few of the specialists abroad hold to the theory of a physical cause.

In our treatment of stuttering and other functional speech disorders, we follow Dr. Blanton's outline. Attention is given first, to vocal re-education. Exercises are given for correct breathing. If the diaphragm and other muscles concerned in breathing can be made to act correctly and easily until this action becomes habituated, a strong resistance to emotional disturbance is formed. A certain amount of drill in corrective phonetics is also given. Second, we try to find the emotional cause, and, if possible, remove it; but if this cannot be done, we attempt to 
change the individual's attitude towards it. As Dr. Blanton says, "Although the facts of life cannot be changed, the meaning of them may be; and with a change of meaning, the emotional reaction to them differs." Our aim is to help the individual bring to light the conflict that is causing his disorder and better adjust himself to reality. Third, we give consideration to physical hygierre. It is necessary that the patient have proper food, the right sleeping arrangements, etc., and often necessary that he have medical attention.

During the school year of 1916-17, we had under instruction 107 children and obtained the following results:

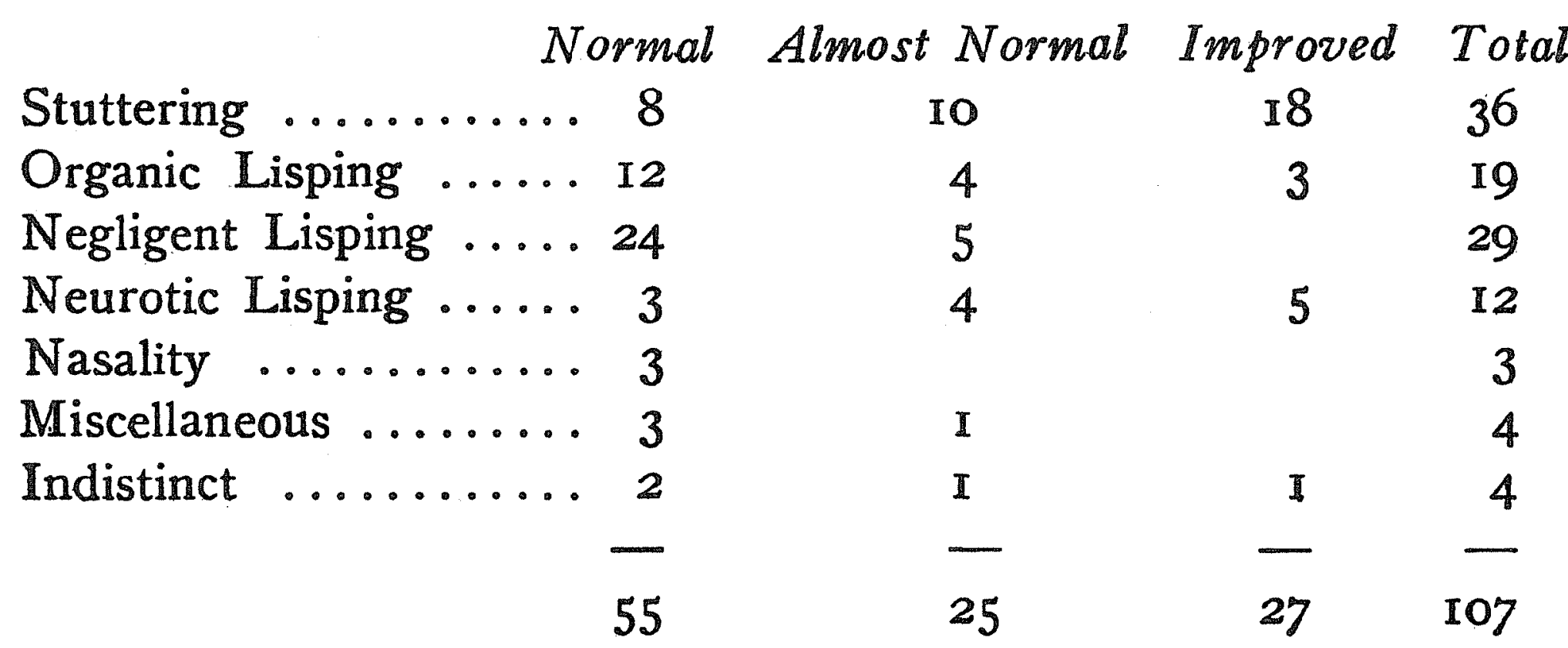

This year we will have under instruction of our special teachers, about 250 children, and in addition to this we hope to work for correction and prevention of speech defects in general by giving instruction in voice culture and corrective phonetics to all of the children of the primary grades. This work will be done by the grade teachers under the supervision of the speech department. It marks an era in the training for correct speech as it aims to set the habits of normal speech at a period in which the child is undergoing great stress. This work will follow the outline given by Dr. Blanton and adapted to the use of the preschool kindergarten and primary grades by Margaret Gray Blanton and Miss Carrie Diebold. 